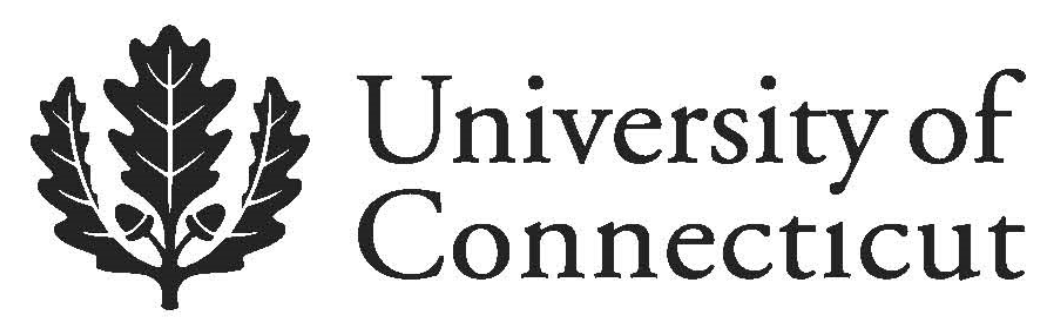

Department of Economics Working Paper Series

\title{
Marginal Deterrence When Offenders Act Sequentially
}

Tim Friehe

University of Bonn

Thomas J. Miceli

University of Connecticut

Working Paper 2014-09

May 2014

365 Fairfield Way, Unit 1063

Storrs, CT 06269-1063

Phone: (860) 486-3022

Fax: (860) 486-4463

http://www.econ.uconn.edu/

This working paper is indexed on RePEc, http://repec.org 


\title{
Marginal Deterrence When Offenders Act Sequentially
}

\author{
Tim Friehe* Thomas J. Miceli ${ }^{\dagger}$
}

May 4, 2014

\begin{abstract}
Marginal deterrence concerns the incentives created by criminal penalties for offenders to refrain from committing more harmful acts. We show that when offenders act sequentially, it is often optimal for the level of the sanction, not just the expected sanction, to rise with the severity of the act, even when enforcement is specific.
\end{abstract}

Keywords: crime, deterrence, marginal deterrence, optimal sanctions

$J E L: K 42$

*University of Bonn, Center for Advanced Studies in Law and Economics, Adenauerallee 24-42, 53113 Bonn, Germany. CESifo, Munich, Germany. E-mail: tim.friehe@uni-bonn.de.

${ }^{\dagger}$ University of Connecticut, Department of Economics, 309 Oak Hall, 365 Fairfield Way, Storrs, CT 062691063. E-mail: Thomas.Miceli@UConn.edu.

Tim Friehe is thankful for the hospitality of the University of Connecticut, where this project was completed during a research visit. 


\section{Introduction}

Marginal deterrence was first discussed in the context of the economic model of crime by Stigler (1970), though as Shavell (1992) notes, the idea was understood by earlier writers such as Bentham and Beccaria. The fundamental point is that if sanctions are set too high for minor acts, then offenders will have no incentive to refrain from committing more harmful acts. This suggests that the sanction should rise with the severity of the act, but that conclusion is not easily demonstrated in the economic model of crime because marginal deterrence can be achieved by varying the likelihood of detection as well as the sanction.

The specific context in which marginal deterrence is examined turns out to be important in deriving the optimal policy. Two scenarios are possible. In the first, an offender chooses between two distinct acts involving different levels of harm. For example, a polluter can discharge a small or a large amount of waste into a river. Alternatively, the offender can act sequentially. For example, a kidnapper may choose to kill his victim if that proves beneficial (e.g., Polinsky and Shavell 2007). In the first example, the offender decides between two acts and commits only one of them, whereas in the second, he commits an initial act (kidnapping) and then later decides whether or not to commit the second (murder). The literature on marginal deterrence has established that, if enforcement efforts can be individualized to the two crimes (i.e., specific deterrence), then the optimal sanctions for both acts are maximal (Shavell 1992, Wilde 1992). ${ }^{1}$ This paper, by contrast, establishes that marginal deterrence in the second scenario often entails a less-than-maximal sanction for the initial act, even when deterrence is specific.

\section{The model}

Risk-neutral offenders with wealth $w$ consider whether or not to undertake act 1 that promises gross benefit $b$, where $b \in[0, B]$ according to $F(b)$. Act 1 causes social harm $h_{1}>0$. The probability of detecting act 1 is $p_{L}$ with probability $\lambda\left(r_{1}\right)$ and $p_{H}$ with probability $\left(1-\lambda\left(r_{1}\right)\right)$, where $\lambda^{\prime}<0<\lambda^{\prime \prime}$ and $p_{H}>p_{L} \geq 0$, such that the expected detection probability is given by

\footnotetext{
${ }^{1}$ Friedman and Sjostrom (1993) and Mookherjee and Png (1994) also contribute on marginal deterrence, albeit using very different assumptions.
} 
$p_{1}\left(r_{1}\right)=\lambda\left(r_{1}\right) p_{L}+\left(1-\lambda\left(r_{1}\right)\right) p_{H}$, with $p_{1}^{\prime}>0>p_{1}^{\prime \prime} .{ }^{2}$ The interpretation is that the commission of act 1 creates some kind of evidence out of the set of possible kinds of evidence, and that law enforcement agencies can make more of a given kind of evidence by expending more resources (e.g., by carefully analyzing the crime scene and interviewing available witnesses). A detected act 1 is punished by the fine $s_{1}$. After the commission of act 1 , offenders observe the evidence created (i.e., whether $p_{L}$ or $p_{H}$ applies). Committing act 2 after act 1 does not generate an additional gross benefit but imposes social harm $h_{2}>0 .{ }^{3}$ Act 2 does, however, change the expected sanction for the composite act to $\theta p_{2}\left(r_{2}\right) s_{2}$, where $r_{2}$ denotes resources invested in the detection of the composite act, $p_{2}^{\prime}>0>p_{2}^{\prime \prime}$, and $s_{2}$ is the fine used to punish perpetrators of the composite act. The level of the detection probability is influenced by $\theta$, a random variable that the offender observes after committing act 1 , where $\theta \in[0, \Theta]$ according to $G(\theta) .{ }^{4}$ The offender commits act 2 only if it lowers his expected punishment; that is, if $\theta \leq \theta_{i}^{*}, i=L, H$, where

$$
\theta_{i}^{*}=\frac{p_{i} s_{1}}{p_{2} s_{2}}
$$

Note that $\theta_{L}^{*}<\theta_{H}^{*}$, so offenders who observe $p_{L}$ are less likely to commit act 2 . Both thresholds are influenced by the law enforcement parameters as follows

$$
\begin{aligned}
& \frac{\partial \theta_{i}^{*}}{\partial s_{1}}=\frac{p_{i}}{p_{2} s_{2}}>0>\frac{\partial \theta_{i}^{*}}{\partial s_{2}}=-\frac{p_{i} s_{1}}{p_{2} s_{2}^{2}} \\
& \frac{\partial \theta_{i}^{*}}{\partial r_{1}}=0>\frac{\partial \theta_{i}^{*}}{\partial r_{2}}=-p_{2}^{\prime} \frac{p_{i} s_{1}}{p_{2}^{2} s_{2}} .
\end{aligned}
$$

Individuals commit act 1 when their gross benefit $b$ exceeds the total expected sanction, which incorporates the offender's later opportunity to commit act 2. Specifically, those offenders for whom $b \geq D$ will commit act 1 , where,

$$
D=\lambda\left[\left(1-G_{L}^{*}\right) p_{L} s_{1}+p_{2}\left(r_{2}\right) s_{2} \int_{0}^{\theta_{L}^{*}} \theta d G\right]+(1-\lambda)\left[\left(1-G_{H}^{*}\right) p_{H} s_{1}+p_{2}\left(r_{2}\right) s_{2} \int_{0}^{\theta_{H}^{*}} \theta d G\right],
$$

using $G_{i}^{*}$ to denote $G\left(\theta_{i}^{*}\right)$. To explain, with probability $\lambda$, circumstances are such that the detection probability for act 1 is low. Even in this scenario, offenders consider undertaking

\footnotetext{
${ }^{2}$ A similar specification is used by Spier (1994) for the accident probability in a tort setting.

${ }^{3}$ Our setup follows Example 1 in Wilde (1992) in this regard.

${ }^{4}$ It is reasonable to assume that the detection probability of the composite act is determined by a different level of resources than that of act 1 alone given its greater severity.
} 
act 2 . With probability $\left(1-G_{L}^{*}\right)$, the offender will refrain from committing act 2 because the context is such that the composite act is associated with a relatively high expected sanction. In that case, the applicable expected sanction is $p_{L} s_{1}$. Otherwise, the offender commits act 2 in addition to act 1 and faces an expected fine of $\theta p_{2} s_{2}$. Alternatively, with probability $(1-\lambda)$, the offender finds himself in a situation in which the evidence implies a high detection probability. In this scenario, the offender will be more likely to commit act 2 in an attempt to lower his expected sanction.

Deterrence is influenced by the law enforcement parameters in the following way

$$
\begin{aligned}
& \frac{\partial D}{\partial s_{1}}=\lambda\left(1-G_{L}^{*}\right) p_{L}+(1-\lambda)\left(1-G_{H}^{*}\right) p_{H}>0 \\
& \frac{\partial D}{\partial s_{2}}=p_{2}\left[\int_{0}^{\theta_{L}^{*}} \theta d G+(1-\lambda) \int_{\theta_{L}^{*}}^{\theta_{H}^{*}} \theta d G\right]>0 \\
& \frac{\partial D}{\partial r_{1}}=\lambda^{\prime}\left[\left(1-G_{L}^{*}\right) p_{L} s_{1}-\left(1-G_{H}^{*}\right) p_{H} s_{1}-p_{2} s_{2} \int_{\theta_{L}^{*}}^{\theta_{H}^{*}} \theta d G\right]>0 \\
& \frac{\partial D}{\partial r_{2}}=p_{2}^{\prime} s_{2}\left[\int_{0}^{\theta_{L}^{*}} \theta d G+(1-\lambda) \int_{\theta_{L}^{*}}^{\theta_{H}^{*}} \theta d G\right]>0 .
\end{aligned}
$$

We can relate our setting to the one in which individuals must commit to undertaking either act 1 or the composite act at the initial decision node (as in Shavell 1992 and Wilde 1992). Committing act 1 only will be privately optimal when $b \geq p_{1}\left(r_{1}\right) s_{1}=\min \left\{p_{1}\left(r_{1}\right) s_{1} ; E[\theta] p_{2}\left(r_{2}\right) s_{2}\right\}$, whereas the composite act is preferable when $b \geq E[\theta] p_{2}\left(r_{2}\right) s_{2}=\min \left\{p_{1}\left(r_{1}\right) s_{1} ; E[\theta] p_{2}\left(r_{2}\right) s_{2}\right\}$.

\section{The analysis}

The social planner maximizes welfare, defined as the sum of gross criminal benefits less harm and enforcement costs, by choosing the sanctions and enforcement levels, subject to the constraints that fines cannot exceed the level of wealth. The Lagrangian function is

$$
\max _{s_{1}, s_{2}, r_{1}, r_{2}, \mu_{1}, \mu_{2}} L=\int_{D}^{B}\left(b-h_{1}-h_{2}\left(\lambda G_{L}^{*}+(1-\lambda) G_{H}^{*}\right)\right) d F-r_{1}-r_{2}+\mu_{1}\left[w-s_{1}\right]+\mu_{2}\left[w-s_{2}\right]
$$


The following conditions determine the optimum: $\mu_{i} \geq 0, L_{\mu_{i}} \geq 0$, and

$$
\begin{aligned}
L_{s_{1}} & =X f(D) \frac{\partial D}{\partial s_{1}}-(1-F(D)) h_{2}\left(\lambda g_{L}^{*} \frac{\partial \theta_{L}^{*}}{\partial s_{1}}+(1-\lambda) g_{H}^{*} \frac{\partial \theta_{H}^{*}}{\partial s_{1}}\right)-\mu_{1}=0 \\
L_{s_{2}} & =X f(D) \frac{\partial D}{\partial s_{2}}-(1-F(D)) h_{2}\left(\lambda g_{L}^{*} \frac{\partial \theta_{L}^{*}}{\partial s_{2}}+(1-\lambda) g_{H}^{*} \frac{\partial \theta_{H}^{*}}{\partial s_{2}}\right)-\mu_{2}=0 \\
L_{r_{1}} & =X f(D) \frac{\partial D}{\partial r_{1}}-(1-F(D)) h_{2} \lambda^{\prime}\left(G\left(\theta_{L}^{*}\right)-G\left(\theta_{H}^{*}\right)\right)-1=0 \\
L_{r_{2}} & =X f(D) \frac{\partial D}{\partial r_{2}}-(1-F(D)) h_{2}\left(\lambda g_{L}^{*} \frac{\partial \theta_{L}^{*}}{\partial r_{2}}+(1-\lambda) g_{H}^{*} \frac{\partial \theta_{H}^{*}}{\partial r_{2}}\right)-1=0 \\
L_{\mu_{i}} \mu_{i} & =0
\end{aligned}
$$

where $X \equiv\left(h_{1}+h_{2}\left[G_{L}^{*}+(1-\lambda)\left(G_{H}^{*}-G_{L}^{*}\right)\right]-D\right)$ is positive by condition (12). Accordingly, the level of deterrence $D$ falls short of the expected harm for act 1 (i.e., $h_{1}+h_{2}\left[G_{L}^{*}+(1-\right.$ $\left.\left.\lambda)\left(G_{H}^{*}-G_{L}^{*}\right)\right]\right)$, which is a standard result when law enforcement is costly.

Our interest lies in the structure of the sanctions for act 1 and the composite act. The possible outcomes are (i) $s_{1}, s_{2}<w$, (ii) $s_{1}<w=s_{2}$, (iii) $s_{1}=w>s_{2}$, or (iv) $s_{1}=w=s_{2}$. In the following, we will provide arguments that rule out the possibilities (i) and (iii), which leaves the possibilities of an increasing sanction scheme and a flat one.

Consider first condition (11). A marginal increase of the sanction for the composite act has two marginal benefits and zero marginal costs, implying that $s_{2}$ will always be maximal. The marginal benefits can be explained as follows. First, an increase in the fine for the composite act increases the level of deterrence, which is valuable since there is underdeterrence. Second, increasing $s_{2}$ makes it less likely that the offender will commit act 2, thereby creating marginal deterrence. The latter effect is due to $\theta_{i}^{*}$ being a decreasing function of $s_{2}$. In other words, the offender is more likely to refrain from act 2 when $p_{i} s_{1}$ looks more favorable in comparison to $p_{2} s_{2}$. In summary, it must be that $\mu_{2}>0$ and $s_{2}^{*}=w$. Similar marginal benefits result from a marginal increase in the resources devoted to the composite act, $r_{2}$, in condition (13). However, an increase in $p_{2}$ has marginal costs of one.

Having established that the sanction for the composite act is maximal, we now analyze whether or not $s_{1}$ is maximal as well. From (10), it is clear that $s_{1}$ has both marginal benefits and marginal costs. The marginal costs stem from the fact that a higher fine for act 1 
undermines marginal deterrence. In order for $\mu_{1}=0$ and $s_{1}<w$, it is required that

$$
X f(D) \frac{\partial D}{\partial s_{1}}=(1-F(D)) h_{2}\left(\lambda g_{L}^{*} \frac{p_{L}}{p_{2} w}+(1-\lambda) g_{H}^{*} \frac{p_{H}}{p_{2} w}\right),
$$

that is, that marginal costs are equal to the marginal benefits for some $s_{1} \in(0, w)$. For $(15)$ to hold, the marginal benefits must exceed (fall short of) marginal costs for small (high) levels of $s_{1}$. The marginal costs of the sanction for act 1 are decreasing when $g^{\prime}$ is small. This implies that an interior solution is only possible when the marginal benefits are decreasing at a faster rate than marginal costs. To shed more light on the possibility of the scheme where $s_{1}<s_{2}=w$, we note that (12) implies

$$
X f(D) \frac{\partial D}{\partial r_{1}}>(1-F(D)) h_{2} \lambda^{\prime}\left(G_{L}^{*}-G_{H}^{*}\right) .
$$

That is, the beneficial impact of more resources $r_{1}$ on the level of deterrence dominates the adverse impact on the level of marginal deterrence. The level of marginal deterrence is adversely affected by an increase in $r_{1}$ because the offender is more likely to find act 2 desirable in the state in which $p_{H}$ applies. Using (15) and (16), we can state a necessary condition for $s_{1}<w$ :

$$
\frac{\partial D / \partial s_{1}}{\partial D / \partial r_{1}}<\frac{\lambda g_{L}^{*} \frac{p_{L}}{p_{2} w}+(1-\lambda) g_{H}^{*} \frac{p_{H}}{p_{2} w}}{\lambda^{\prime}\left(G_{L}^{*}-G_{H}^{*}\right)} .
$$

The absolute reduction in $r_{1}$ required to hold deterrence constant after a marginal increase in $s_{1}$ (the LHS) falls short of the reduction required to keep the expected harm from act 2 constant (the RHS). In other words, when the social planner attempts an exchange of $r_{1}$ for $s_{1}$ to save on enforcement costs while keeping deterrence constant, this increases the expected social costs from offenders engaging in act $2 .^{5}$ Using all of the information contained in (12) in condition (10), we deduce that the following is required for $s_{1}<w$ to be part of a maximum:

$$
\frac{\partial D / \partial s_{1}}{\partial D / \partial r_{1}}=\frac{(1-F(D)) h_{2}\left(\lambda g_{L}^{*} \frac{p_{L}}{p_{2} w}+(1-\lambda) g_{H}^{*} \frac{p_{H}}{p_{2} w}\right)}{1+(1-F(D)) h_{2} \lambda^{\prime}\left(G_{L}^{*}-G_{H}^{*}\right)}
$$

which goes beyond condition (17) by including the marginal resource costs of $r_{1}$.

\footnotetext{
${ }^{5}$ The centrality of (17) for the result of an increasing sanction scheme can also be made apparent by supposing that it holds the other way around. Then, it is possible to increase $s_{1}$ and lower $r_{1}$ to keep $D$ constant, thereby decreasing the expected harm from act 2 .
} 
Proposition 1 In a sequential two-act model, the sanction for the less harmful act may be less than maximal despite the availability of specific enforcement. The sanction for the more harmful (composite) act will always be set at the maximal level.

Proof. The proposition follows from the preceding argument using condition (18) and is corroborated by a numerical illustration in Section 4 .

\section{Numerical illustration}

We illustrate the possibility of an increasing sanction scheme with a simple example. Assume that $b$ and $\theta$ are uniformly distributed in $[0,1]$, and that $p_{L}=.02, p_{H}=.2, h_{1}=.5, h_{2}=.8$, $w=10, \lambda\left(r_{1}\right)=e^{-r_{1}}$, and $p_{2}\left(r_{2}\right)=1-e^{-.25 r_{2}}$. In this case, we obtain the optimal policy vector $\left(s_{1}^{F B}, s_{2}^{F B}, r_{1}^{F B}, r_{2}^{F B}\right)=(6.049,10, .471,6.167)$, which yields welfare of $W=.084$. It follows that $\lambda=.624, p_{2}=.786, \theta_{L}^{*}=.004, \theta_{H}^{*}=.023$, and $D=.085$. Note that the equilibrium levels of $\theta_{i}^{*}$ imply that the probability that offenders will actually undertake act 2 after act 1 is very small. Nevertheless, the presence of act 2 produces an optimal sanction scheme in which the level of $s_{1}$ is smaller than the level of the maximal fine by a considerable margin. Quite intuitively, the optimal level of $s_{1}$ approaches $w$ when $h_{2}$ decreases. Reducing $h_{2}$ to .2 , for example, while maintaining the other assumptions from above, gives $\left(s_{1}^{F B}, s_{2}^{F B}, r_{1}^{F B}, r_{2}^{F B}\right)=$ $(9.024,10, .270,3.515)$, whereas $h_{2}=.1$ yields a flat sanction scheme; that is, $s_{1}^{F B}=s_{2}^{F B}=w$.

\section{References}

Friedman, D., and W. Sjostrom, 1993. Hanged for a sheep: The economics of marginal deterrence. Journal of Legal Studies 22, 345-366.

Mookherjee, D. and I. Png. 1994. Marginal Deterrence in Enforcement of Law. Journal of Political Economy 102: 1039-1066.

Polinsky, A.M., and S. Shavell, 2007. The theory of public enforcement of law. In: Polinsky, A.M., Shavell, S. (eds.), Handbook of Law and Economics 1. Elsevier, Amsterdam.

Shavell, S., 1992. A note on marginal deterrence. International Review of Law and Economics 
12, 345-355.

Spier, K.E., 1994. Settlement bargaining and the design of damage awards. Journal of Law, Economics, \& Organization 10, 84-95.

Stigler, G. 1970. The optimum enforcement of laws. Journal of Political Economy 78, 526-536.

Wilde, L.L., 1992. Criminal choice, nonmonetary sanctions, and marginal deterrence: a normative analysis. International Review of Law and Economics 12, 345-355. 